OPEN ACCESS

Edited by:

Graham Dow,

ETH Zürich, Switzerland

Reviewed by:

Dimitrios Fanourakis,

Technological Educational Institute

of Crete, Greece

Andreas M. Savvides,

Agricultural Research Institute, Cyprus

Peter Lehmann,

ETH Zürich, Switzerland

*Correspondence:

David A. Grantz

dagrantz@ucanr.edu

Specialty section:

This article was submitted to Plant Development and EvoDevo,

a section of the journal

Frontiers in Plant Science

Received: 13 December 2019

Accepted: 02 June 2020

Published: 25 June 2020

Citation:

Grantz DA, Karr $M$ and

Burkhardt J (2020) Heterogeneity

of Stomatal Pore Area Is Suppressed

by Ambient Aerosol in the Homobaric

Species, Vicia faba.

Front. Plant Sci. 11:897.

doi: $10.3389 /$ fpls.2020.00897

\section{Heterogeneity of Stomatal Pore Area Is Suppressed by Ambient Aerosol in the Homobaric Species, Vicia faba}

\author{
David A. Grantz ${ }^{1,2 *}$, Marcus Karr ${ }^{1}$ and Juergen Burkhardt ${ }^{2}$ \\ ${ }^{1}$ Department of Botany and Plant Sciences, Kearney Agricultural Center, University of California, Riverside, Riverside, CA, \\ United States, ${ }^{2}$ Institute of Crop Science and Resource Conservation, University of Bonn, Bonn, Germany
}

Stomatal pore area is heterogeneous across leaf surfaces. This has been considered as "patchy stomatal conductance," and may have substantial implications for photosynthetic efficiency. Aerosols have always been important elements of plant environments, but their effects on stomatal control of plant water relations, and stomatal heterogeneity specifically, have not been considered. Here we evaluate the spatial coordination of pore area in the glabrous and homobaric leaves of Vicia faba grown under two aerosol treatments and measured at four levels of VPD. We construct a large dataset ( $n>88,000$ discrete comparisons) of paired pore areas and distances between the pores. Plants were grown in ambient urban air and in filtered air (FA) to determine the effect of ambient aerosol on stomatal properties. Pore area exhibited spatial organization, as well as considerable variability among closely co-located pores. The difference between pore areas was positively correlated with the distance between the pores, in both aerosol treatments and at all VPDs. However, aerosol deposition reduced both the magnitude of variability between pores and the rate at which this variability increased with pore separation distance. These data support previous conclusions that deposition of hygroscopic aerosol may create a thin aqueous film across the leaf surface that connects neighboring stomata to each other and to the leaf interior. Aerosol impacts on stomatal heterogeneity and gas exchange are not adequately considered in current assessments of stomatal control.

Keywords: aerosol, climate change, gas exchange, humidity, particulate matter, patchy stomata, vapor pressure deficit

\section{INTRODUCTION}

Heterogeneous stomatal opening across the surface of individual leaves may result in stomatal "patchiness," random variation, or spatially coherent trends in pore area across the surface. Stomatal heterogeneity has been observed in many species (Downton et al., 1988, 1990; Terashima et al., 1988; Sharkey and Seemann, 1989; Terashima, 1992; Pospisilova and Santrucek, 1994; Haefner et al., 1997; Weyers and Lawson, 1997; Beyschlag and Eckstein, 1998; Mott and Buckley, 1998, 2000). Non-uniform pore areas and resulting uneven conductance for $\mathrm{CO}_{2}$ and water vapor complicate standard measurements and calculations of gas exchange parameters. Heterogeneity 
observed at all stages of leaf elongation in Rosa shows that this is not a transient developmental feature (Fanourakis et al., 2015). Under conditions of high boundary layer conductance, stomatal heterogeneity may be detrimental to gas exchange efficiency, but under conditions of low wind or large leaves, which reduce boundary layer conductance, and under conditions of low overall stomatal conductance, heterogeneity may improve photosynthetic efficiency (Buckley et al., 1999). This reflects the effects of evaporative cooling of the leaf on fluxes and gradients of both water and $\mathrm{CO}_{2}$, and the transport efficiency of those pores that remain widely open. The significance and ubiquity of stomatal heterogeneity and its relationship with environmental conditions (Cheeseman, 1991; Gunasekera and Berkowitz, 1992; Cardon et al., 1994) as well as the role of aerosol deposition (Burkhardt and Grantz, 2017) in generating such heterogeneity have not been adequately considered.

Areas of coordinated stomatal behavior may range from a few $\mathrm{mm}$ to a few $\mathrm{cm}$ in extent (Terashima, 1992; Mott and Buckley, 1998, 2000; Mott and Peak, 2007) and are often bounded by veins, particularly in heterobaric leaves (Siebke and Weis, 1995; Haefner et al., 1997; Weyers and Lawson, 1997; Mott and Buckley, 2000). Patterns of heterogeneity can be transient, with patches of coherent stomatal response migrating within and even between areoles of heterobaric leaves (Kamakura et al., 2012), even though gas diffusion is restricted to areoles defined by vasculature with bundle sheath extensions (Terashima, 1992; Mott and Buckley, 2000).

Spatially coherent stomatal behavior is also observed in homobaric leaves (Kappen et al., 1987; Loreto and Sharkey, 1990; Mott and Parkhurst, 1991; Terashima, 1992; Eckstein et al., 1996; Mott and Buckley, 2000; Kamakura and Furukawa, 2008). This heterogeneity is less patchy and more characterized by trends across the leaf surface, from leaf base to tip (Nardini et al., 2008), margin to midrib (Weyers and Lawson, 1997), and more generally across the lamina (Terashima et al., 1988). Patches observed as ${ }^{14} \mathrm{CO}_{2}$ fixation in homobaric $V$. faba (Terashima et al., 1988) were larger than in many heterobaric species and could be considered gradients across the leaf, with greater heterogeneity within the patches than in heterobaric species (Spence, 1987; Terashima et al., 1988). Stomatal aperture in homobaric Commelina communis (Smith et al., 1989) exhibited gradients as high as $3 \mu \mathrm{m}$ per $\mathrm{mm}$ and $20 \mu \mathrm{m}$ from leaf edge to midrib. This behavior may be observed even in epidermal peels exposed to uniform physical and chemical conditions. The distribution of pore opening often approximates a normal distribution (e.g., V. faba; Laisk et al., 1980). This variance within and between leaves obscures spatial patterns across individual leaves (Weyers and Lawson, 1997), so that heterogeneity in homobaric leaves remains poorly characterized.

Uneven levels of conductance across the surfaces of individual leaves have been associated with discrepancies in estimation of intercellular $\mathrm{CO}_{2}\left(\mathrm{C}_{\mathrm{i}}\right)$. Values calculated from measured fluxes of $\mathrm{CO}_{2}$ and water vapor exceeded directly measured values by up to 15\% (Buckley et al., 1999; Boyer, 2015a,b; Hanson et al., 2016). This suggested a pathway for water efflux that was unavailable to $\mathrm{CO}_{2}$ influx, potentially peristomatal transpiration from around the stomatal pores (Maier-Maercker, 1983; Grantz,
1990), or cuticular transpiration from across the epidermis between the pores (Kerstiens, 1996; Boyer et al., 1997; Hanson et al., 2016). Alternatively, stomatal heterogeneity could distort the calculation of $\mathrm{C}_{\mathrm{i}}$ (Terashima et al., 1988) as measurements of steady state gas exchange reflect the leaf-wise average of highly dynamic heterogeneous individual pores and patches of pores (Siebke and Weis, 1995).

Increased evaporative demand (leaf to air vapor pressure difference; VPD) reduces stomatal conductance and increases stomatal heterogeneity (Sharkey and Seemann, 1989; Downton et al., 1990; Haefner et al., 1997). Experimentally imposed local changes in humidity at the leaf surface altered the apertures of stomata within the affected area, and those of stomata up to $0.4 \mathrm{~cm}$ away, outside of the directly affected area. The linkage was apparently through epidermal turgor, although this mechanism may operate most effectively over short distances (Haefner et al., 1997; Mott et al., 1997, 1999; Mott and Franks, 2001). Variability in mesophyll biochemistry (Osmond et al., 1999) and xylem water relations may become more effective at larger scales of leaf or branch (Buckley and Mott, 2000).

Aerosol deposition (Burkhardt and Grantz, 2017) may affect both the asymmetric flux pathways for water and $\mathrm{CO}_{2}$ (Grantz et al., 2018) and stomatal heterogeneity. Deposition of hygroscopic, particularly chaotropic, aerosol (Tsigaridis et al., 2006; Pringle et al., 2010; Burkhardt and Grantz, 2017) reduces surface tension and results in development of thin liquid films on leaf surfaces (Eiden et al., 1994; Dutcher et al., 2010; Burkhardt and Hunsche, 2013; Burkhardt and Grantz, 2017; Fernandez et al., 2017). The liquid films penetrate into stomatal pores (Eichert et al., 1998, 2008; Basi et al., 2014; Kaiser, 2014), providing a liquid phase linkage between the saturated leaf apoplast and the dry atmosphere. This pathway is not under diffusional (i.e., stomatal) control and thus water loss from this pathway through evaporation at the leaf surface increases as VPD increases, even in species such as $V$. faba that exhibit strong closing response to increasing VPD (Pariyar et al., 2013; Grantz et al., 2018). The presence of liquid films can be visualized by electrical conductance measurements (Burkhardt and Eiden, 1994; Burkhardt et al., 1999; Burkhardt and Hunsche, 2013) and by electron micrography (Burkhardt and Grantz, 2017; Burkhardt et al., 2018; Grantz et al., 2018). Aerosol deposition reduces stomatal apertures (Burkhardt et al., 2001a; Burkhardt, 2010; Burkhardt and Grantz, 2017; Grantz et al., 2018) while increasing both water flux (Burkhardt et al., 2001a; Grantz et al., 2018) and minimum (cuticular) leaf conductance (Burkhardt and Pariyar, 2014, 2016; Grantz et al., 2018).

We hypothesized that aerosol-induced surface moisture may link individual pores across the leaf surface by providing a more homogeneous hydraulic and vapor pressure environment, thereby reducing stomatal heterogeneity despite potential desiccating effects of liquid phase water loss and the previously documented reduction in pore area (Grantz et al., 2018). Here we characterize the distribution of stomatal pore areas, a subject of previous consideration (Laisk et al., 1980; Spence, 1987; Gorton et al., 1989; Terashima, 1992; Weyers and Lawson, 1997) and the role of aerosol deposition on this heterogeneity, which has not 
previously been considered. We analyze a previously available dataset of 3600 direct microscopic pore area measurements (Grantz et al., 2018) to create a novel database of 88,200 discrete pore to pore comparisons of distances between the pores $(\mathrm{d})$ and the differences between their pore areas $(\Delta \mathrm{A})$. We evaluate the distribution of pore areas, the local and larger scale heterogeneity of stomatal opening, and the effect of four levels of VPD and two levels of ambient aerosol on these characteristics.

\section{MATERIALS AND METHODS}

\section{Plant Material}

Plants of Vicia faba (L.) were grown from seed as described previously (Grantz et al., 2018) in plastic pots in greenhouses at the University of Bonn, Germany. Plants received complete nutrient solution (Ferty 3, Planta Düngemittel $\mathrm{GmbH}$, Hohenstauf, Germany) weekly and irrigation as needed.

Plants were randomly assigned either to a greenhouse ventilated with ambient air (AA) or an adjacent greenhouse ventilated with filtered air (FA). Filtration removed nearly all particles (Pariyar et al., 2013; Grantz et al., 2018). The aerosol was typical of ambient particulate matter in central Europe (about 35\% ionic; see Grantz et al., 2018 and references therein). Aerosol concentration in the AA greenhouse (cloud chamber condensation nuclei counter; TSI 3783; TSI, Shoreview, MN, United States) was 6-7 $610^{9}$ particles $\mathrm{m}^{-3}$. This was reduced in the FA greenhouse by $99 \%$ to $5-10 \times 10^{6} \mathrm{~m}^{-3}$; confirming previous measurements (e.g., Pariyar et al., 2013). Other environmental parameters including temperature, relative humidity and concentrations of ozone were similar in the greenhouses (see Supplementary Figures S1, S2 in Grantz et al., 2018). Plants were exposed to natural daylength and sunlight (approximately $70 \%$ of ambient irradiance).

Measurements were obtained 5 weeks after planting on one leaflet of leaf 5 or 6 (youngest fully expanded; mean leaflet area about $32 \mathrm{~cm}^{2}$ ) when plants had been exposed for 3-4 weeks in the greenhouses. Leaflets remained attached to intact plants during all measurements.

\section{Measurement of Pore Area at Controlled VPD}

Plants were transported from Bonn to Kiel, Germany. Pore area measurements (see Grantz et al., 2018 for further details) were obtained while leaf to air VPD was controlled in a flowthrough gas exchange system with an integrated inverted video microscope (Kaiser and Kappen, 1997, 2000; Kaiser, 2009). The gas exchange cuvette was held at constant temperature $\left(25^{\circ} \mathrm{C} \pm 0.1^{\circ} \mathrm{C}\right)$ and irradiance (PPFD $=450 \pm 25 \mu \mathrm{mol}$ $\left.\mathrm{m}^{-2} \mathrm{~s}^{-1}\right)$. Dew point was held at $23.15,19.0,14.0$, and $5.0^{\circ} \mathrm{C}$ $\left( \pm 0.05^{\circ} \mathrm{C}\right)$, yielding VPD of $0.33,0.97,1.6$, and $2.3 \mathrm{kPa}$ and $\mathrm{RH}$ of $90 \%, 68 \%, 50 \%$, and $27 \%$, at abaxial leaf temperature $\left(25^{\circ} \mathrm{C}\right.$; Type $\mathrm{K}$ thermocouple, $0.075 \mathrm{~mm})$. Air circulation in the cuvette $(1 \mathrm{~m}$ $\mathrm{s}^{-1}$ ) yielded laminar boundary layer conductance of $1300 \mathrm{mmol}$ $\mathrm{m}^{-2} \mathrm{~s}^{-1}$ (Kaiser, 2009).

Nine plants were used for each of the AA and FA treatments (Experiment 1, Grantz et al., 2018). Measurements on plants subjected to the two aerosol treatments were alternated on successive days. Pore area was measured on 50 stomata per leaflet, on the abaxial surface, within the $1 \mathrm{~cm}^{2}$ area of a predefined grid. The sample area was located away from major veins and leaf margins. The 50 stomata represented about $0.2 \%$ of the stomata in the $1 \mathrm{~cm}^{2}$ viewing area. The location (pore center) and focus depth (narrowest part of the pore center) of each pore was stored electronically (Kaiser, 2009) to allow rapid reimaging at each VPD.

\section{Data Analysis}

Data were stored with plant, leaf and pore identifiers, pore area, and pore coordinates in the Cartesian framework defined across the microscope stage (Kaiser, 2009). The area of each pore was determined as an idealized ellipse determined by the directly measured length and width of each pore, taken as the major and minor axes (Grantz et al., 2018). The difference in pore area $(\Delta \mathrm{A})$ between pairs of stomata was evaluated as a function of their separation distance (d) across the leaf surface.

Values of $d$ were calculated from the coordinates of the center of each pore using the Pythagorean Theorem executed in a custom Python program (v. 3.6; Python Software Foundation ${ }^{1}$ ). Unique pair comparisons $[\mathrm{C}(50,2)=(50)(50-1) / 2=1225$ per leaflet] were evaluated. With 9 leaflets/aerosol treatment, 2 treatments, and 50 pores/leaflet, there were 900 unique pores and with 4 levels of VPD there were 88,200 unique comparisons of $\Delta \mathrm{A}$ vs. $\mathrm{d}$. The maximum value of $\mathrm{d}$ was about $1.4 \mathrm{~cm}$, representing the diagonal of the $1 \mathrm{~cm}^{2}$ square examined on each leaf.

Regressions of $\Delta \mathrm{A}$ on $\mathrm{d}$ were calculated in Sigma Plot, $\mathrm{v}$. 13.0 (Systat Software, San Jose, CA, United States; Regression Wizard). Normality [Kolmogorov-Smirnov (K-S) Test] and equality of variance (Brown-Forsythe Test) were generally not satisfied $(P<0.050)$. The sole exception was FA at low VPD, which was normally distributed. Mean $\Delta \mathrm{A}$ (Table 1) and regression coefficients (Table 2) were evaluated by Two-Way ANOVA (Sigma Plot) with mean separation using the HolmSidak Multiple Range Test.

\footnotetext{
${ }^{1}$ https://www.python.org/
}

TABLE 1 | Means of the differences between pore areas $(\Delta A)$.

\begin{tabular}{lccc}
\hline & \multicolumn{3}{c}{ Mean difference in pore area $\left(\Delta \mathbf{A} ; \mu \mathbf{m}^{2}\right)$} \\
\cline { 2 - 4 } VPD & Ambient Air (AA) & Filtered Air (FA) & AA vs. FA \\
\hline $0.33 \mathrm{kPa}$ & $37.6 \pm 0.32$ (a) & $47.6 \pm 0.37$ (b) & $P<0.001$ \\
$0.97 \mathrm{kPa}$ & $42.5 \pm 0.36$ (c) & $56.1 \pm 0.45$ (d) & $P<0.001$ \\
$1.6 \mathrm{kPa}$ & $43.6 \pm 0.37$ (d) & $53.6 \pm 0.43$ (c) & $P<0.001$ \\
$2.3 \mathrm{kPa}$ & $39.9 \pm 0.39$ (b) & $45.7 \pm 0.40$ (a) & $P<0.001$
\end{tabular}

Lower case letters within columns refer to differences between VPD levels within each aerosol treatment. $P$ values in the right hand column refer to differences between aerosol treatments within VPD levels. Means were analyzed by Two-Way ANOVA with mean separation (right hand column) by the Holm-Sidak method. The $\triangle A \times V P D$ interaction was generally significant. 


\section{RESULTS}

\section{Pore Location}

The imaging system facilitated collection of a large number of clear photomicrographs (Figure 1). At all levels of stomatal opening, both within each VPD and across the levels of VPD, the pores were well characterized as ellipses, allowing the area (A) of each pore to be calculated from the directly measured length and width. Leaves of $V$. faba exhibited uniformly kidney-shaped guard cells (Figure 1), lacking specialized stomatal subsidiary cells and the bundle sheath extensions that play a role in stomatal patchiness in heterobaric species.

The distances (d) between pores were distributed approximately normally (Figure 2). Neither the shape of the distribution nor the magnitude of the distance scale differed between leaves exposed during leaf development to ambient aerosol (AA) or to FA (cf. Figures 2A,B). These characteristics were also stable across the levels of VPD (not shown), despite the potential for leaf shrinkage due to reduced leaf water content (not measured) at elevated VPD.

\section{Pore Area}

The large data set available for this study allowed a robust characterization of the distributions of pore area $(\mathrm{A})$ in the two aerosol treatments over a range of VPDs (Figure 3 ). At low VPD $(0.33 \mathrm{kPa})$ the distributions of $\mathrm{A}$ in both AA (Figure $3 \mathrm{~A}$ )

TABLE 2 | Linear regression coefficients of the relationships between the difference in pore area $(\Delta \mathrm{A})$ and the distance between the pores $(\mathrm{d})$.

\begin{tabular}{|c|c|c|c|}
\hline VPD & Ambient Air (AA) & Filtered Air (FA) & AA vs. FA \\
\hline \multicolumn{4}{|c|}{ (A) Intercept $\left(\mu \mathrm{m}^{2}\right)$} \\
\hline $0.33 \mathrm{kPa}$ & $\begin{array}{c}35.2 \pm 0.75 \text { (a) } \\
{[P<0.0001]}\end{array}$ & $\begin{array}{c}40.4 \pm 0.88 \text { (a) } \\
{[P<0.0001]}\end{array}$ & $P<0.001$ \\
\hline $0.97 \mathrm{kPa}$ & $\begin{array}{c}36.8 \pm 0.85 \text { (a) } \\
{[P<0.0001]}\end{array}$ & $\begin{array}{c}48.7 \pm 1.07 \text { (b) } \\
{[P<0.0001]}\end{array}$ & $P<0.001$ \\
\hline $1.6 \mathrm{kPa}$ & $\begin{array}{c}41.0 \pm 0.87 \text { (b) } \\
{[P<0.0001]}\end{array}$ & $\begin{array}{c}48.2 \pm 1.01 \text { (b) } \\
{[P<0.0001]}\end{array}$ & $P<0.001$ \\
\hline $2.3 \mathrm{kPa}$ & $\begin{array}{c}36.6 \pm 0.93 \text { (a) } \\
{[P<0.0001]}\end{array}$ & $\begin{array}{c}44.4 \pm 0.94 \text { (c) } \\
{[P<0.0001]}\end{array}$ & $P<0.001$ \\
\hline \multicolumn{4}{|c|}{ (B) Slope $\left(\mu \mathrm{m}^{2} \mathrm{~cm}^{-1}\right)$} \\
\hline $0.33 \mathrm{kPa}$ & $\begin{array}{c}4.6 \pm 1.34 \text { (a) } \\
\text { Adj } r^{2}=0.0010 \\
{[P=0.0007]}\end{array}$ & $\begin{array}{c}13.6 \pm 1.50 \text { (a) } \\
\text { Adj } r^{2}=0.0072 \\
{[P<0.0001]}\end{array}$ & $P<0.001$ \\
\hline $0.97 \mathrm{kPa}$ & $\begin{array}{c}11.1 \pm 1.51 \text { (b) } \\
\text { Adj } r^{2}=0.0048 \\
{[P<0.0001]}\end{array}$ & $\begin{array}{c}14.1 \pm 1.84(\mathbf{a}) \\
\text { Adj } r^{2}=0.0052 \\
{[P<0.0001]}\end{array}$ & $P=0.208$ \\
\hline $1.6 \mathrm{kPa}$ & $\begin{array}{c}5.1 \pm 1.55 \text { (a) } \\
\text { Adj } r^{2}=0.0009 \\
{[P=0.001]}\end{array}$ & $\begin{array}{c}10.3 \pm 1.74(\mathbf{a}) \\
\text { Adj } r^{2}=0.0031 \\
{[P<0.0001]}\end{array}$ & $P=0.026$ \\
\hline $2.3 \mathrm{kPa}$ & $\begin{array}{c}6.4 \pm 1.66(\mathbf{a b}) \\
\text { Adj } r^{2}=0.0013 \\
{[P=0.0001]}\end{array}$ & $\begin{array}{c}2.5 \pm 1.62 \text { (b) } \\
\text { Adj } r^{2}=0.0001 \\
{[P=0.1188]}\end{array}$ & $P=0.093$ \\
\hline
\end{tabular}

$P$ values in brackets refer to the individual regression coefficients. Lower case letters within columns refer to differences between VPD levels within each aerosol treatment. $P$ values in the right hand column refer to differences between coefficients for each aerosol treatment within VPD levels. Coefficients were analyzed by Two-Way ANOVA with mean separation by the Holm-Sidak method.

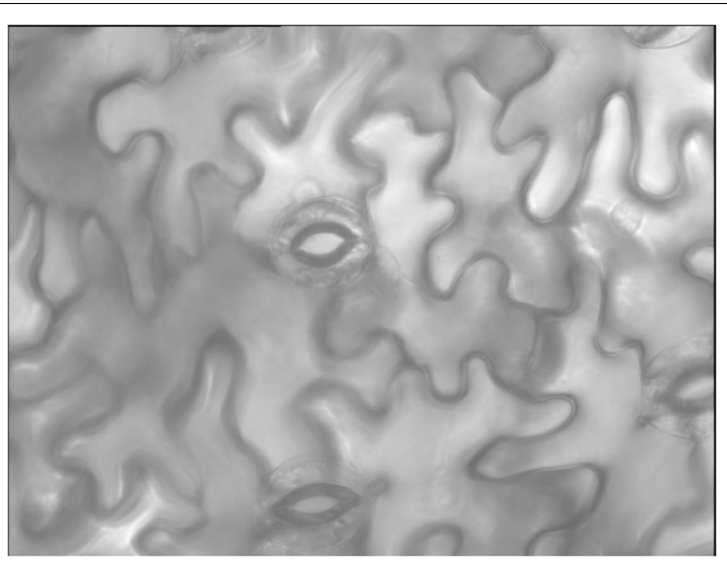

FIGURE 1 | Typical stomatal pores whose areas (A) were measured. Representative example at low VPD $(0.33 \mathrm{kPa})$. Micrograph dimensions $300 \times 300 \mu \mathrm{m}$.

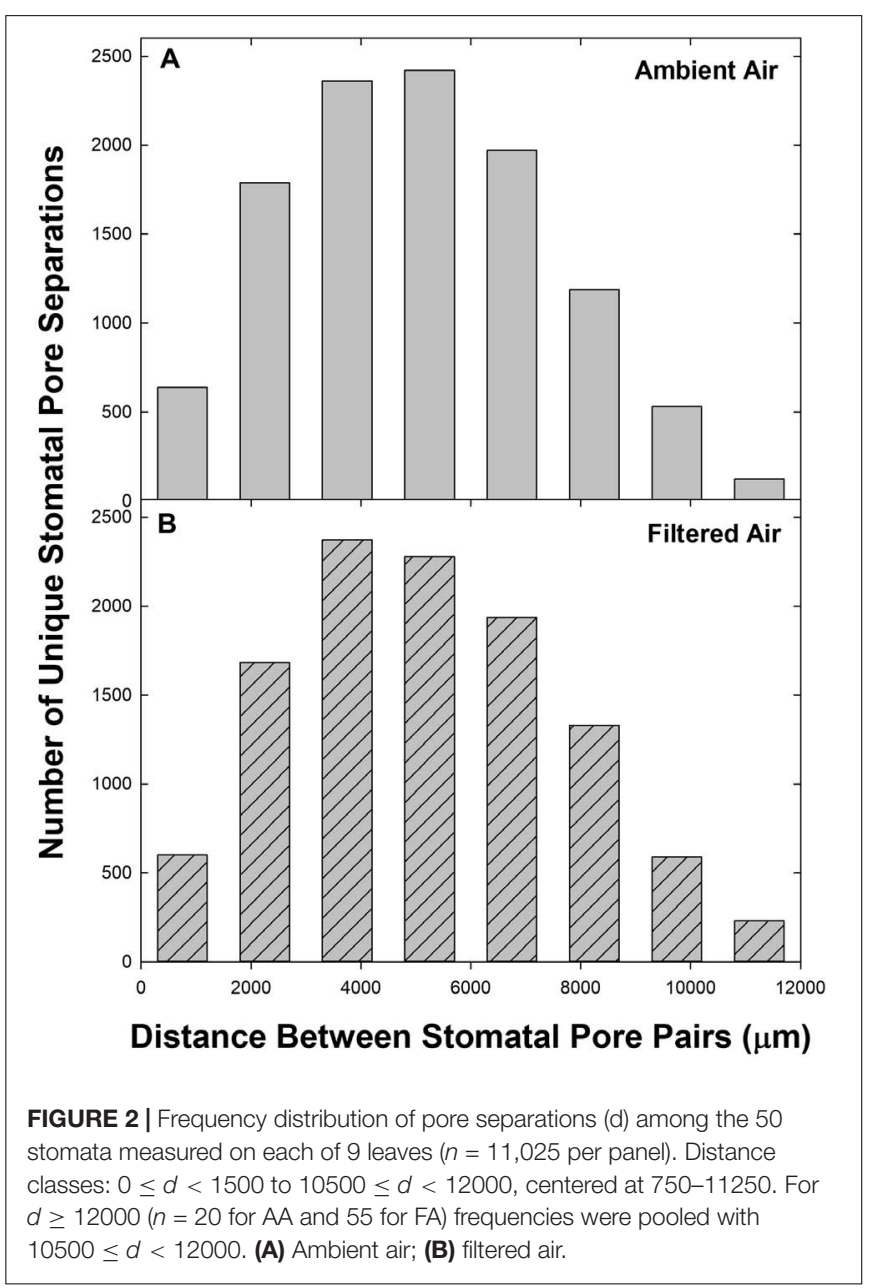

and FA (Figure 3B) treatments were approximately bell shaped, although only the FA treatment (Figure 3B) formally satisfied the Kolmogorov-Smirnov test for normality (K-S statistic of 0.661 ). All other distributions exhibited $\mathrm{K}-\mathrm{S}<0.001$. 


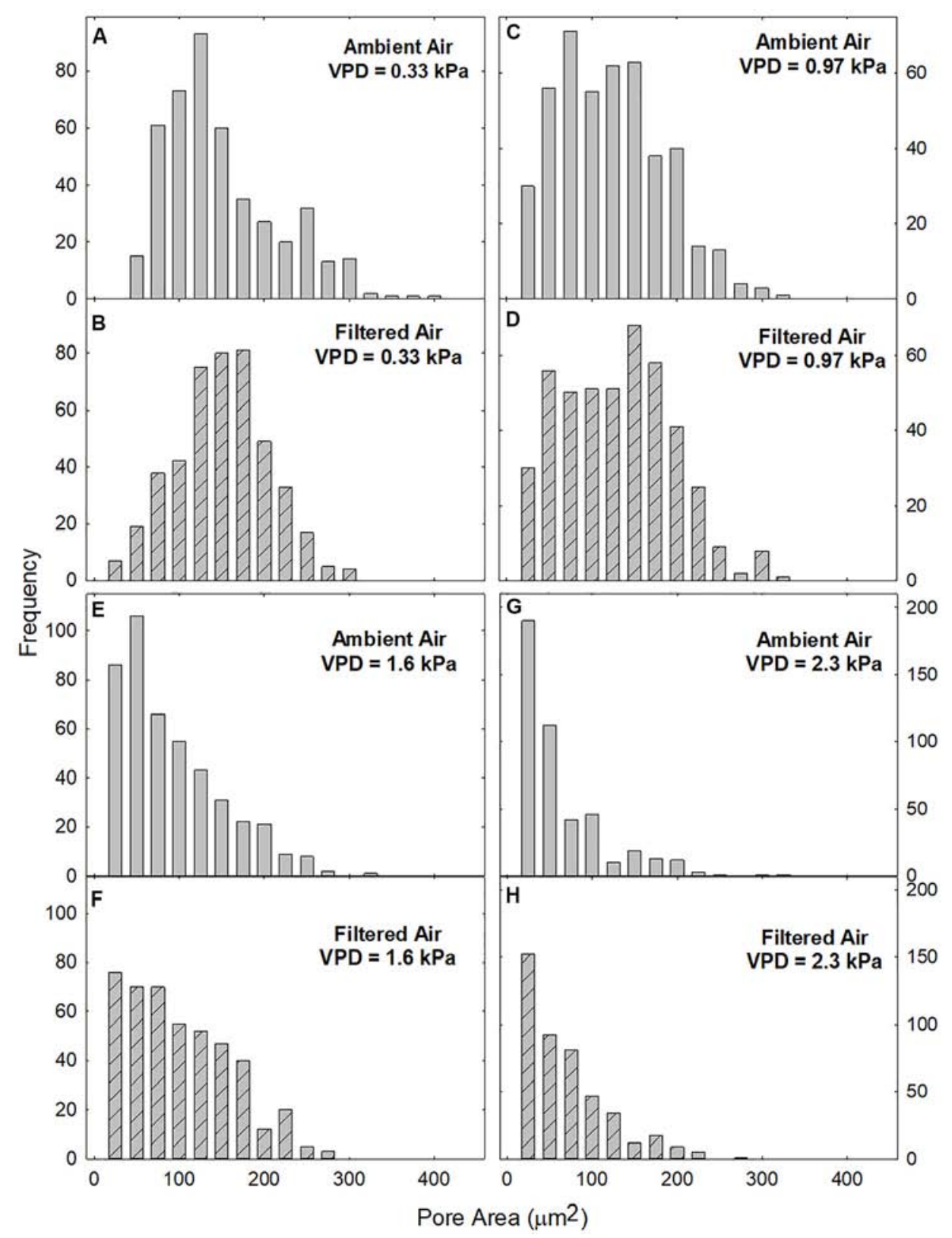

FIGURE 3 | Frequency distribution of pore areas (A) at different levels of evaporative demand (VPD), in leaves exposed to ambient (gray bars; A,C,E,G) or filtered (hatched bars; B,D,F,H) air. Area classes: $0 \leq A<50$ to $400 \leq A<450$, centered at 25-425. The smallest visible bars represent 1 pore.

The distributions of A were similar in AA and FA leaves at all levels of VPD (cf. Figures 3A-H). VPD did not differ during plant growth between the $\mathrm{AA}$ and $\mathrm{FA}$ treatments but was varied experimentally during measurement of pore areas. Skewing toward the origin increased with VPD (Figure 3) so that the quasi-bell shaped distribution was no longer evident at $1.6 \mathrm{kPa}$ (Figures 3E,F) or $2.3 \mathrm{kPa}$ (Figures 3G,H) in either aerosol treatment.

In most cases, increasing VPD reduced pore area, i.e., with greater deviation below the 1:1 line (Figure 4). In FA at $0.97 \mathrm{kPa}$ the pattern was different. The less open pores closed in response to increased VPD, but pores initially exhibiting A $>190 \mu \mathrm{m}^{2}$ (Figure 4A; red circles) did not close below the initial A. Individual stomata behaved consistently over the range of VPDs. Those with small pore areas at $0.33 \mathrm{kPa}$ exhibited small areas at higher VPD. Many that were only slightly open at low VPD closed completely at higher VPD. With increasing VPD, the number of such stomata and their initial pore areas increased (horizontal part in lower left end of each curve; Figure 4).

Leaves exposed to ambient aerosol also exhibited greater skewing toward the origin. This reduction in magnitude was 


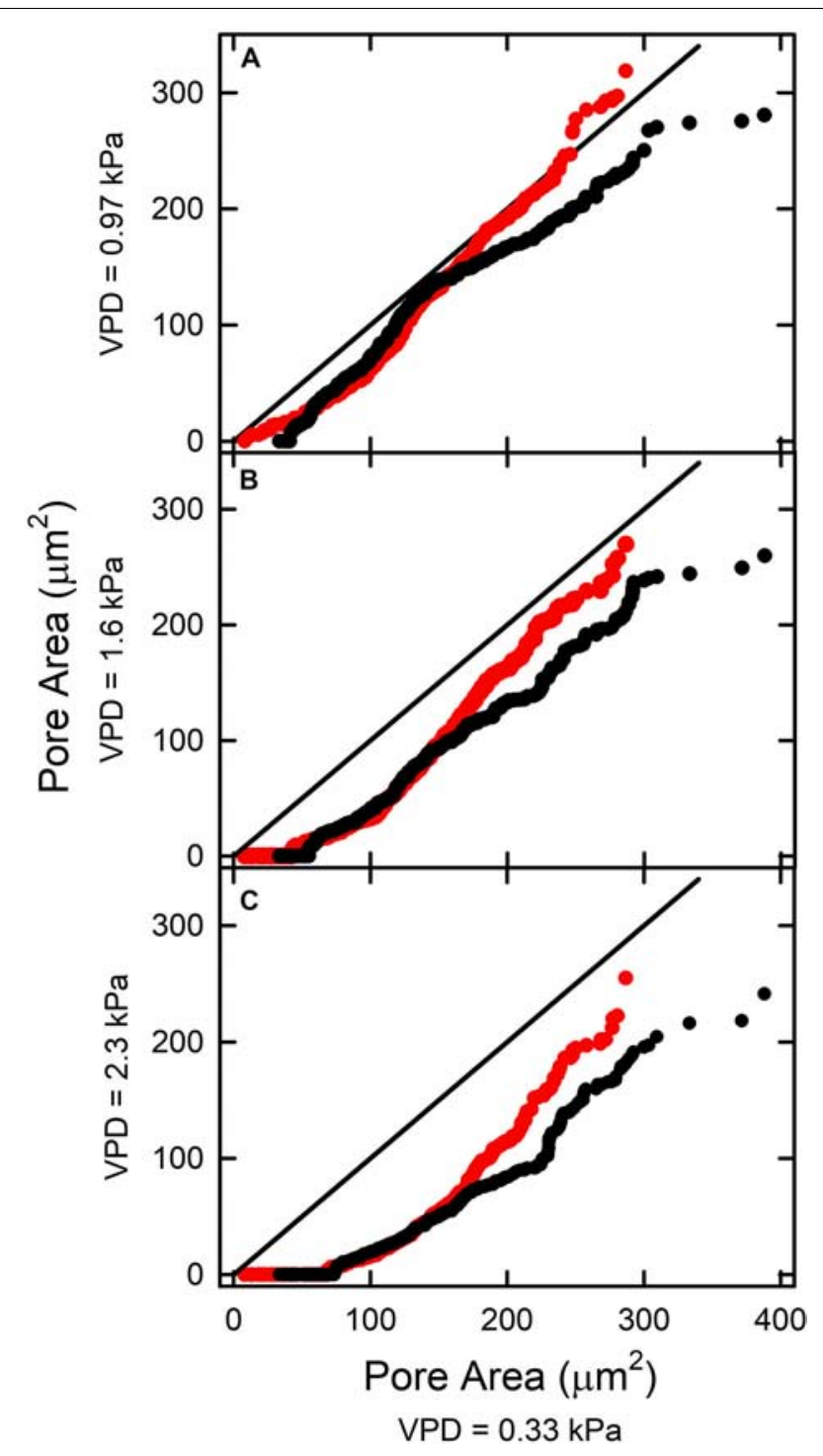

FIGURE 4 | The relationship between stomatal pore area at elevated VPD [(A) $0.97 \mathrm{kPa}$; (B) $1.6 \mathrm{kPa}$; (C) $2.3 \mathrm{kPa}$ and pore area measured at low VPD $(0.33 \mathrm{kPa})$. The AA treatment is shown in black, and the FA treatment in red. The solid line represents the 1:1 line.

reflected in reduced mean $\triangle \mathrm{A}$ between pores in $\mathrm{AA}$ relative to FA observed at all levels of VPD (Table 1). In general, the AA treatment closed more substantially than the FA as VPD was increased, particularly at greater initial pore area at low VPD (Figure 4). Among stomata with areas below $180 \mu \mathrm{m}^{2}$ at $0.33 \mathrm{kPa}$, there was little effect of aerosol on the relationships between pore area at low VPD and at higher VPD. This point of divergence between AA and FA was similar at all VPD (Figures 4A-C). Above this value of initial opening, pore areas in FA and AA diverged, with AA smaller than FA. This was observed from $0.33 \mathrm{kPa}$ to $0.97 \mathrm{kPa}$ (Figure 4A), even though the response of FA to VPD was minimal among the more open pores. The sensitivity to aerosol increased with pore area observed at low VPD, but did not change substantially with increasing VPD.

\section{Stomatal Heterogeneity}

We had hypothesized that stomatal heterogeneity, both $\Delta \mathrm{A}$ between closely co-located pores and the increase of $\Delta \mathrm{A}$ with $\mathrm{d}$ between more distant pores, would be reduced by aerosol deposition. The suggested mechanism, involving liquid films on the leaf surface, is illustrated in Figure 5 showing an open stoma at the left and a closed stoma at the right. Regardless of pore area, water evaporates from the surface of the leaf (blue arrows), potentially drawing both from the surface water (Figure 5; blue lines) and from soil, tissue, and apoplastic storage (continuity indicated by green lines). Conventional transpiration from the apoplast (green arrows) occurs through the open pore (left side) but this diffusive transport is almost completely blocked by stomatal closure (right side).

In contrast, a continuous liquid film developing from deliquescence of deposited hygroscopic aerosol may spread across large areas of the leaf and penetrate into the stomatal pores. This liquid path through the pore reduces stomatal control of water loss. This may degrade epidermal water status by enhancing water loss, while also reducing the variability in the hydraulic and humidity environments across the leaf surface (Figure 5). While reduced epidermal water content might increase stomatal heterogeneity, the uniform environment under the liquid film might lead to more uniform epidermal water status and reduce heterogeneity.

We observed a reduction in heterogeneity in the ambient aerosol treatment. The intercept of $\Delta \mathrm{A}$ on $\mathrm{d}$ was significantly lower in AA than FA at all VPD (Table 2A), reflecting reduced heterogeneity among closely co-located pores (extrapolated to zero separation). Exposure to aerosol also significantly reduced both mean $\Delta \mathrm{A}$ (Table $\mathbf{1}$ and Figure 6) and median $\Delta \mathrm{A}$ (Figure 7) at all levels of VPD. The considerable local variability is illustrated by the closely positioned pores in Figure 1, exhibiting $\Delta \mathrm{A}$ of about $25 \%$ despite the guard cells bordering on the same epidermal cell.

Although there were fewer pores at small and large separations (Figure 2), the distributions of both mean $\Delta \mathrm{A}$ (Figure 6) and median $\Delta \mathrm{A}$ (Figure 7) revealed a consistent increase with $\mathrm{d}$ over the entire range. This was observed in both AA and FA leaves, but the increase in $\Delta \mathrm{A}$ with $\mathrm{d}$ was reduced by aerosol (Figures 6,7 ). The slope of $\Delta \mathrm{A}$ on $\mathrm{d}$ was significantly reduced in AA relative to FA at VPD of $0.33 \mathrm{kPa}$ and $1.6 \mathrm{kPa}$ (Table $2 \mathrm{~B}$; c.f. Figures 6G,H, 7G,H). Slopes did not differ at $0.97 \mathrm{kPa}$ or $2.3 \mathrm{kPa}$. This reflects a general reduction in the increase in heterogeneity with distance within the $1 \mathrm{~cm}^{2}$ sample area caused by aerosol exposure. The median analysis is presented, along with the mean, because the data often varied from normality.

The impact of VPD was less consistent. In AA, mean $\triangle \mathrm{A}$ (Table 1) and the intercept of $\Delta \mathrm{A}$ at $d=0$ (Table 2A) increased with initial increase of VPD from $0.33 \mathrm{kPa}$ through 0.97 to $1.6 \mathrm{kPa}$ but declined at $2.3 \mathrm{kPa}$. In contrast, in $\mathrm{FA}$, the mean and intercept of $\triangle \mathrm{A}$ increased with VPD from 0.33 to $0.97 \mathrm{kPa}$, but began to decline at $1.6 \mathrm{kPa}$ and declined further at $2.3 \mathrm{kPa}$. The pattern of response of $\Delta \mathrm{A}$ over all pores (mean) and among closely spaced 


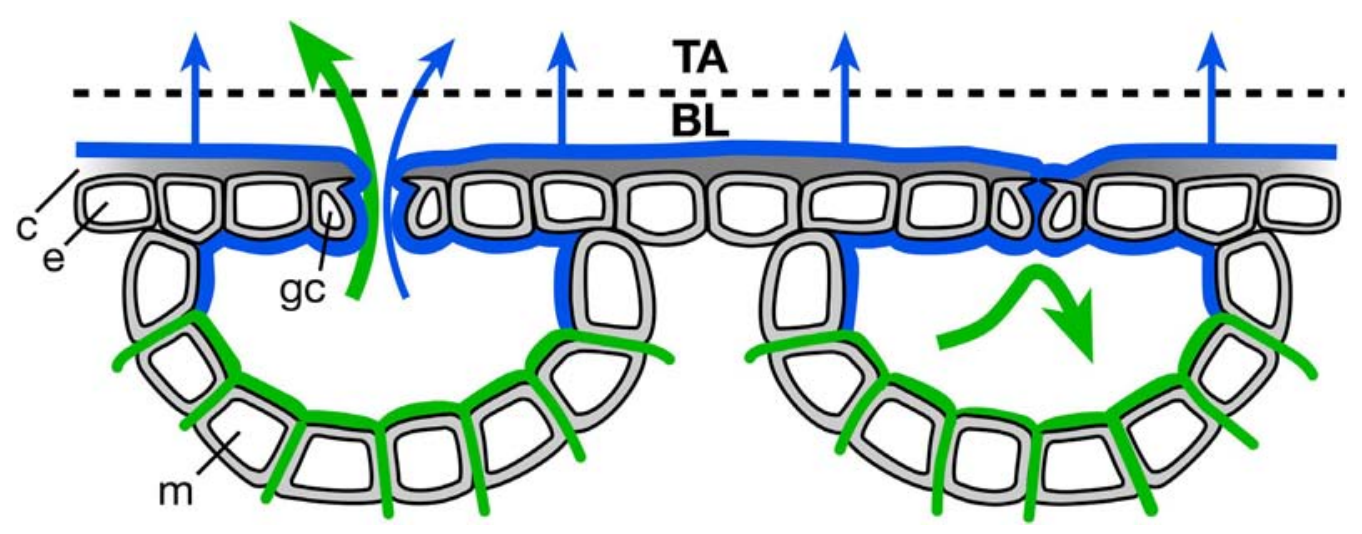

FIGURE 5 | The hypothesized role of thin liquid films in reducing microenvironmental variability across the leaf surface. Blue lines represent liquid formed by condensation to deposited hygroscopic aerosol on the leaf surface, including that which penetrates the stomatal pores; blue arrows represent the evaporative flux of water derived from this liquid. Green lines represent conventional apoplastic liquid water derived from the soil-root-xylem pathway passing through and around mesophyll cells $(\mathrm{m})$; green arrows represent the much larger evaporative flux of this water when stomata are open (left side) and its elimination by stomatal closure (right side). Evaporation occurs from aerosol-condensed water with both open (left side) and closed (right side) stomata, as liquid continuity between leaf interior and exterior is maintained largely independently of stomatal pore area determined by guard cell (gc) turgor. The leaf boundary layer (BL) is uniformly humidified across the leaf surface and the osmotic environment of the cuticle (c) and underlying epidermis (e) is made more homogeneous by the presence of a liquid film. All fluxes (blue and green arrows) eventually pass through the $B L$ and enter the mixed free atmosphere (TA), representing water loss from the leaf.

pores (intercept) was similar in the aerosol treatments, but the decline began at lower VPD in the absence of aerosol. In contrast, the slope of $\triangle \mathrm{A}$ on $\mathrm{d}$, reflecting larger scale heterogeneity, did not differ consistently between levels of VPD (Table 2B).

Heterogeneity of stomatal pore area was composed of two components, variability among pore areas that was not related to the distance between the pores (Table 2A; left-most bars, Figures 6,7$)$, and variability which trended systematically with d (Table 2B; distributions, Figures 6, 7). The first type of variability was expressed both as local heterogeneity between closely colocated pores, and as a component of the magnitude of $\Delta \mathrm{A}$ between more distant pores. Large values of $\Delta \mathrm{A}\left(>35 \mu \mathrm{m}^{2}\right)$ were observed among neighboring pores in both $\mathrm{AA}$ and FA. In all cases, local variability in $\Delta \mathrm{A}$ among neighboring pores was greater than the increase in $\Delta \mathrm{A}$ with $\mathrm{d}$ across the observation area of $1.4 \mathrm{~cm}$ (Figures 6, 7).

\section{DISCUSSION}

This study had two objectives, to characterize the distribution of individual pore areas over a range of VPD levels, and to elucidate the role of ambient aerosol in stomatal regulation of plant water relations. The first objective is advanced through analysis of an unusually large number of non-destructively imaged pore areas, acquired previously (Grantz et al., 2018). Previous experiments have approached this objective by imaging many fewer pores, either the same pores repeated over time in epidermal peels (Gorton et al., 1989) or different pores at different times in leaf impressions (Smith et al., 1989). We advance the second objective with a novel analysis of aerosol impacts on stomatal heterogeneity. We showed previously that transpiration per unit stomatal aperture and minimum leaf conductance both increased following aerosol deposition (Burkhardt et al., 2001a;
Grantz et al., 2018). No previous analyses have considered whether aerosol deposition might also affect the uniformity of stomatal opening.

\section{Pore Area Distribution}

Stomatal opening is characterized by a strong element of randomness that often results in a quasi-normal (bell-shaped) distribution of pore areas (Gorton et al., 1989; Terashima, 1992; Weyers and Lawson, 1997). Our observations confirm earlier reports, including in $V$. faba (Laisk et al., 1980; Kappen et al., 1987; Spence, 1987), of large within-leaf variability with quasinormally distributed pore areas, particularly at VPD $=0.33 \mathrm{kPa}$ and $0.97 \mathrm{kPa}$. There was large heterogeneity even among nearly contiguous pores, as observed previously in $V$. faba and other species. For example, adjacent stomata of homobaric tobacco (Nicotiana tabacum) ranged from fully closed to fully open (Pospisilova and Santrucek, 1994).

At higher VPD (1.6 kPa and $2.3 \mathrm{kPa})$, the distributions skewed toward the origin, with a larger proportion of closed pores and reduced mean and median values, as described previously (Grantz, 1990; Grantz et al., 2018). These highly skewed distributions may also belong to theoretically normal distributions that extend into the imaginary territory of negative pore area (Laisk et al., 1980). The maintenance of the bell-shaped distribution even as mean and median pore area declined, reflects synchronous, parallel, and potentially coordinated responses, of similar magnitude by pores of different initial areas and in different locations across the leaf (Saxe, 1979; Spence et al., 1983; Kappen et al., 1987; Spence, 1987). This coherent behavior resembles an emergent property (Mott and Buckley, 2000; Mott and Peak, 2007) but the mechanism of such coordination remains unknown. Elevated VPD increases transpiration and degrades epidermal water status, suggesting metabolic and hydropassive 


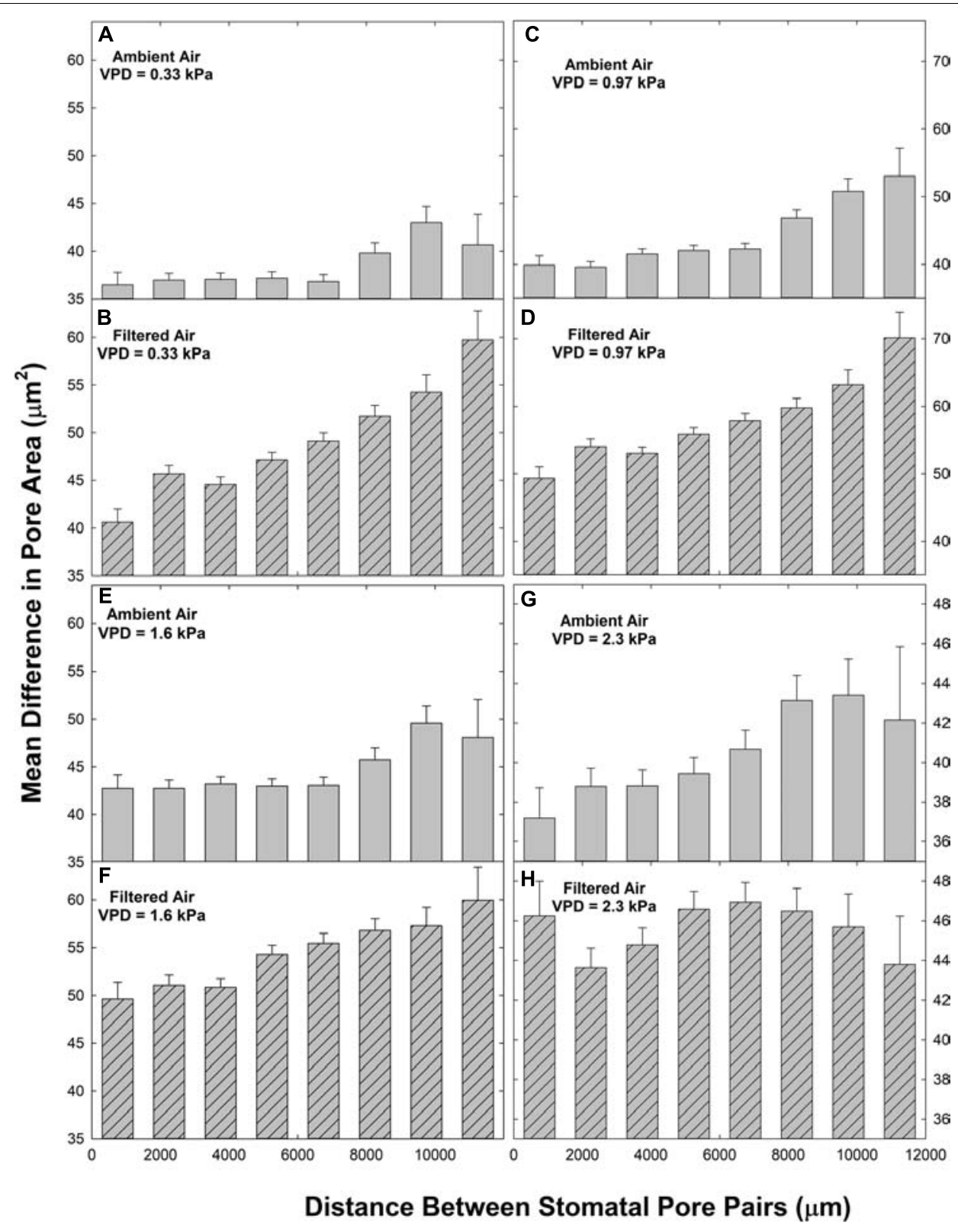

FIGURE 6 | Relationships between the paired difference between pore area $(\triangle \mathrm{A})$ and the distance separating the pores (d) in ambient air (AA; gray bars; A,C,E,G) and filtered air (FA; hatched bars, B,D,F,H) at different levels of evaporative demand (VPD), presented as mean \pm s.e. Distance classes as in Figure 2.

responses of guard cells to epidermal water relations (Mott and Franks, 2001; Buckley, 2005, 2019).

The deposition of hygroscopic aerosol on the leaf surface may act similarly. The presence of thin liquid films lining stomatal pores provides a non-diffusive liquid pathway for water loss (Burkhardt et al., 2001b; Grantz et al., 2018), potentially increasing transpiration and degrading epidermal water status. Hygroscopic, particularly chaotropic, aerosol enhances the formation of such films by deliquescence and facilitates their spread across the leaf surface and into stomatal pores by reducing the surface tension of the liquid on the leaf surface (Monteith, 1957; Eiden et al., 1994; Dutcher et al., 2010;
Burkhardt and Hunsche, 2013; Burkhardt and Grantz, 2017; Fernandez et al., 2017). Electrical conductance measurements (Burkhardt and Eiden, 1994; Burkhardt et al., 1999; Burkhardt and Hunsche, 2013) and electron micrography (Grantz et al., 2018) demonstrate these films and their penetration into stomatal pores (Eichert et al., 1998, 2008; Basi et al., 2014; Kaiser, 2014). The resulting hydraulic linkage of apoplast to the leaf boundary layer is associated with a reduction of mean pore area and skewing of areas toward the origin (Burkhardt et al., 2001a, 2012; Burkhardt, 2010; Pariyar et al., 2013; Grantz et al., 2018).

The current study demonstrates an apparent 3-way synergy between elevated VPD, initial stomatal opening at low VPD, 


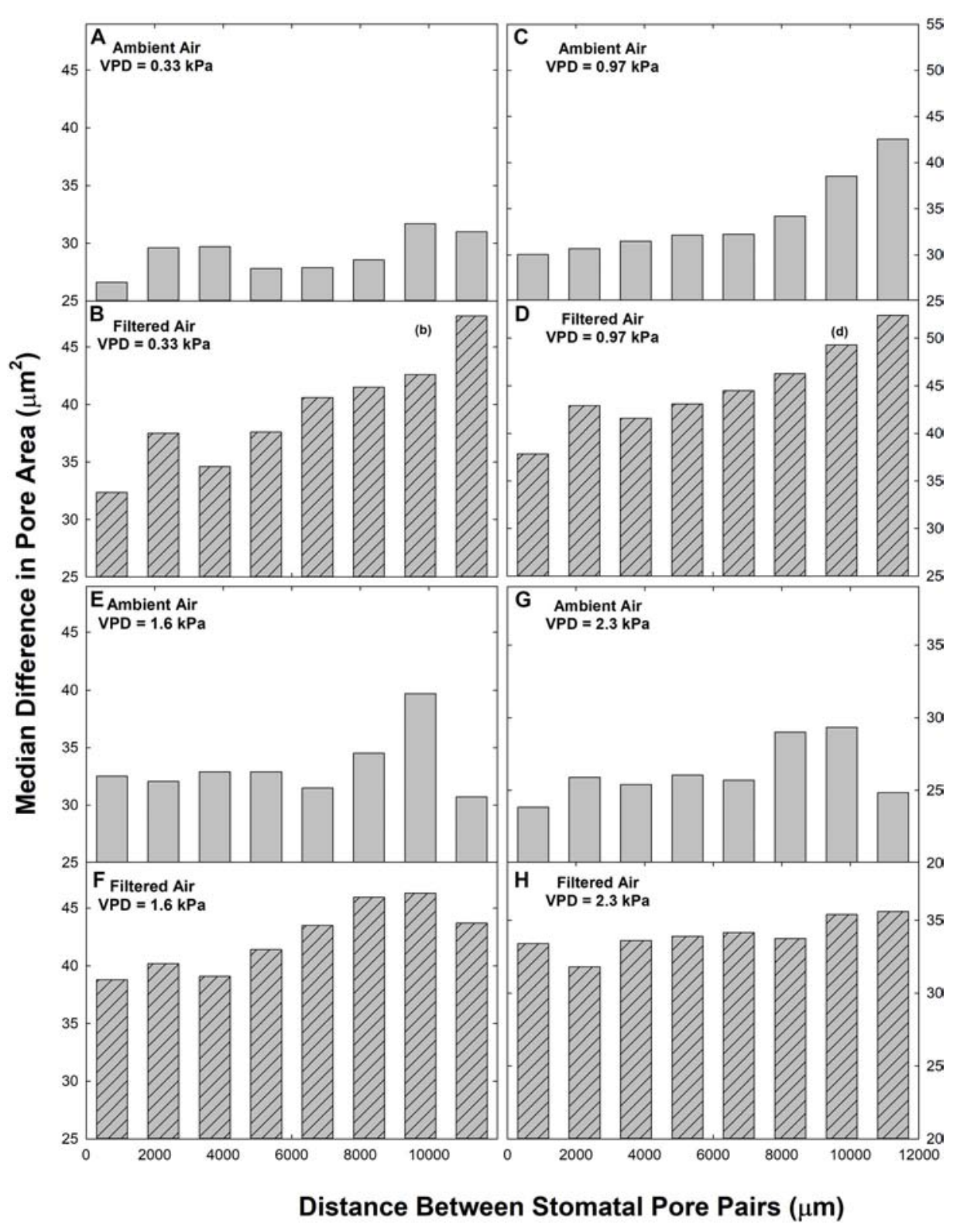

FIGURE 7 | Relationships between the paired difference between pore area $(\triangle \mathrm{A})$ and the distance separating the pores (d) in ambient air (AA; gray bars; $\mathbf{A}, \mathbf{C , E}, \mathbf{G}$ ) and filtered air (FA; hatched bars, B,D,F,H) at different levels of evaporative demand (VPD), presented as median. Distance classes as in Figure 2.

and deposition of aerosol, consistent with a cumulative effect on epidermal water relations. At pore areas above about $180 \mathrm{\mu m}^{2}$ (at VPD $=0.33 \mathrm{kPa}$ ) the dynamics of $\mathrm{AA}$ and FA differ as VPD increased. The role of initial opening may reside in the conditions required to sustain liquid water on the leaf surface. This depends on the humidity of the BL which is substantially affected by transpiration. The role of aerosol deposition is to induce water accumulation on the leaf surface from unsaturated air, which becomes more significant at elevated VPD. In the absence of aerosol (FA), condensation on the leaf surface requires approximately $100 \% \mathrm{RH}$, but the presence of hygroscopic aerosol (AA) reduces this requirement substantially (e.g., to 75\% $\mathrm{RH}$ for deliquescence of $\mathrm{NaCl}$ aerosol; Burkhardt and Grantz, 2017).

\section{Pore Area Heterogeneity}

Vicia faba is homobaric, without bundle sheath extensions or specialized stomatal subsidiary cells. This removes within-areole coordination of gaseous and water potential environments and suggests weaker coordination among stomata at local scale and potentially greater coordination at larger scale than in heterobaric species. In the present study, variability among closely co-located pores was large. This baseline level of $\Delta \mathrm{A}$ was a dominant component of mean and median $\Delta \mathrm{A}$ at all levels of pore 
separation and at all levels of VPD. At larger scale, there was a consistent increase of $\triangle \mathrm{A}$ with $\mathrm{d}$ at all VPD and both aerosol treatments. However, the increase in $\triangle \mathrm{A}$ with distance was less than the local variability observed between closely spaced stomata. This reflects poor coordination between individual pores that was degraded further with greater separation within the $1.4 \mathrm{~cm}$ scale of our observations.

Degraded epidermal water status is associated with increased stomatal heterogeneity (Sharkey and Seemann, 1989; Downton et al., 1990; Haefner et al., 1997). However, in the present study, VPD did not consistently increase the magnitude of $\Delta \mathrm{A}$ among neighboring pores, increasing only at moderate levels then declining.

The increased water loss per unit stomatal opening observed in the AA treatment (Grantz et al., 2018), suggested that aerosol could increase stomatal heterogeneity. However, this was not observed. Aerosol decreased heterogeneity among neighboring pores at all levels of VPD and reduced the rate of increase of $\Delta \mathrm{A}$ with d at all VPD.

The liquid film at the leaf surface in the presence of aerosol may link stomata over potentially large areas of the leaf surface by making the near-surface micro-environment more homogeneous. This unifying effect may be more significant than the effect of the liquid film on increased water loss and potential impacts on epidermal water status.

Theories of stomatal optimization (Cowan and Farquhar, 1977) and of cavitation avoidance (Sperry et al., 2017), implicitly consider stomata as a population, whether at the leaf, branch or larger scale (Mott and Peak, 2007). Under conditions of high boundary layer conductance, heterogeneity may be detrimental, but in low wind or with large leaves it may improve gas exchange efficiency. This may explain similar growth of plants grown in AA or FA conditions (unpublished observations) in the slowly ventilated greenhouse, but degraded water use efficiency of AA leaves in the rapidly stirred cuvette of a gas exchange system (Pariyar et al., 2013). By reducing heterogeneity, aerosol deposition could reduce the errors in calculated values of $\mathrm{C}_{\mathrm{i}}$, potentially a factor that distinguishes gas exchange measurements made under controlled environment conditions from those made in more aerosol-rich field conditions.

\section{CONCLUSION}

Stomatal heterogeneity and patchy conductance remain enigmatic (Gunasekera and Berkowitz, 1992). Stomatal patchiness represents stronger stomatal coordination at local scale and poorer coordination at larger scale than predicted by true randomness (Sharkey and Seemann, 1989; Downton et al., 1990; Haefner et al., 1997; Lawson et al., 1998; Mott and Buckley, 2000; Mott and Peak, 2007). While heterogeneity among individual pore areas has been considered as noise (e.g., Cheeseman, 1991) it has more recently been seen as informative regarding the physiological bases of stomatal opening mechanics (Laisk et al., 1980), responses to environment (Mott et al., 1997; Mott and Buckley, 2000) and of the signal processing required for attainment of quasi-optimal stomatal behavior (Cheeseman,
1991; Cardon et al., 1994; Siebke and Weis, 1995; Kaiser and Kappen, 1997; Mott and Peak, 2007). Environmental drivers of coordination among individual members of populations of stomatal pores, including light and VPD, have been considered critical components of the stomatal regulatory system. Aerosol deposition to leaves has not been considered as often, but may play an important role.

We demonstrate, using a very large data set, that stomatal pore areas may be described as quasi-normally distributed, even as mean and median values change with VPD and aerosol deposition. We show that VPD and aerosol deposition both reduce mean pore area and the differences among pores, both at local and greater scale within individual leaves of homobaric $V$. faba. Synergy of these two ubiquitous environmental factors with the previously unexplored factor of initial stomatal opening, suggests linkage through impacts on epidermal water relations. The aerosol exposure in this experiment was typical of regional European particulate pollution (Putaud et al., 2010), and the study material a short-lived herbaceous annual. These effects may be greater in more hirsute and longer-lived leaves, and in more heavily polluted environments (Kuki et al., 2008; Yang et al., 2015). Aerosol impacts on leaf water relations and gas exchange, mediated by the degree of stomatal opening and its heterogeneity, may be more significant than commonly realized. Further research focused on the control elements regulating stomatal pore area (e.g., Buckley, 2019) and on their interactions with aerosol deposition (e.g., Burkhardt and Grantz, 2017) may be increasingly relevant to characterization of local and global budgets of water and carbon.

\section{DATA AVAILABILITY STATEMENT}

The datasets generated for this study are available on request to the corresponding author.

\section{AUTHOR CONTRIBUTIONS}

DG and JB conceived of the experiments. DG conducted the gas exchange and pore dimension experiments and analyzed the data. MK developed the software for spatial analysis. All authors contributed to interpretation of the results and wrote the manuscript.

\section{FUNDING}

The authors acknowledge funding from the University of California, Riverside Research Allocation Process, the Deutsche Forschungsgemeinschaft (DFG; BU 1099/7-2), and from USDA NIFA Project No. CA-R-BPS-5005-H.

\section{ACKNOWLEDGMENTS}

The authors thank H. Kaiser for interesting discussions leading up to this analysis as well as considerable assistance with the measurements. 


\section{REFERENCES}

Basi, S., Burkhardt, J., Noga, G., and Hunsche, M. (2014). Hygroscopic salts support the stomatal penetration of glyphosate and influence its biological efficacy. Weed Biol. Manag. 14, 186-197. doi: 10.1111/wbm.12046

Beyschlag, W., and Eckstein, J. (1998). Stomatal patchiness. Prog. Bot. 59, 283-298. doi: 10.1007/978-3-642-80446-5_10

Boyer, J. S. (2015a). Impact of cuticle on calculations of the CO2 concentration inside leaves. Planta 242, 1405-1412. doi: 10.1007/s00425-015-2378-1

Boyer, J. S. (2015b). Turgor and the transport of CO2 and water across the cuticle (epidermis) of leaves. J. Exp. Bot. 66, 2625-2633. doi: 10.1093/jxb/erv065

Boyer, J. S., Wong, S. C., and Farquhar, G. D. (1997). CO2 and water vapor exchange across leaf cuticle (epidermis) at various water potentials. Plant Physiol. 114, 185-191. doi: 10.1104/pp.114.1.185

Buckley, T. N. (2005). The control of stomata by water balance. New Phytol. 168, 275-292. doi: 10.1111/j.1469-8137.2005.01543.x

Buckley, T. N. (2019). How do stomata respond to water status? New Phytol. 224, 21-36. doi: 10.1111/nph.15899

Buckley, T. N., Farquhar, G. D., and Mott, K. A. (1999). Carbon-water balance and patchy stomatal conductance. Oecologia 118, 132-143. doi: 10.1007/ s004420050711

Buckley, T. N., and Mott, K. A. (2000). Stomatal responses to non-local changes in PFD: evidence for long distance hydraulic interactions. Plant Cell Environ. 23, 301-309. doi: 10.1046/j.1365-3040.2000.00552.x

Burkhardt, J. (2010). Hygroscopic particles on leaves: nutrients or desiccants? Ecol. Monogr. 80, 369-399. doi: 10.1890/09-1988.1

Burkhardt, J., Basi, S., Pariyar, S., and Hunsche, M. (2012). Stomatal penetration by aqueous solutions - an update involving leaf surface particles. New Phytol. 196, 774-787. doi: 10.1111/j.1469-8137.2012.04307.x

Burkhardt, J., and Eiden, R. (1994). Thin water films on coniferous needles. Atmos. Environ. 28, 2001-2011. doi: 10.1016/1352-2310(94)90469-3

Burkhardt, J., and Grantz, D. A. (2017). Plants and atmospheric aerosols. Prog. Bot. 78, 369-406. doi: 10.1007/124_2016_12

Burkhardt, J., and Hunsche, M. (2013). "Breath figures" on leaf surfaces-formation and effects of microscopic leaf wetness. Front. Plant Sci. 4:422. doi: 10.3389/fpls. 2013.00422

Burkhardt, J., Kaiser, H., Goldbach, H., and Kappen, L. (1999). Measurements of electrical leaf surface conductance reveal recondensation of transpired water vapour on leaf surfaces. Plant Cell Environ. 22, 189-196. doi: 10.1046/j.13653040.1999.00387.x

Burkhardt, J., Kaiser, H., Kappen, L., and Goldbach, H. E. (2001a). The possible role of aerosols on stomatal conductivity for water vapour. Basic Appl. Ecol. 2, 351-364. doi: 10.1078/1439-1791-00062

Burkhardt, J., Koch, K., and Kaiser, H. (2001b). Deliquescence of deposited atmospheric particles on leaf surfaces. Water Air Soil Pollut. Focus 1, 313-321. doi: 10.1007/978-94-010-9026-1_31

Burkhardt, J., and Pariyar, S. (2014). Particulate pollutants are capable to 'degrade' epicuticular waxes and to decrease the drought tolerance of Scots pine (Pinus sylvestris L.). Environ. Pollut. 184, 659-667. doi: 10.1016/j.envpol.2013.04.041

Burkhardt, J., and Pariyar, S. (2016). How does the VPD response of isohydric and anisohydric plants depend on leaf surface particles? Plant Biol. 18, 91-100. doi: $10.1111 /$ plb.12402

Burkhardt, J., Zinsmeister, D., Grantz, D. A., Vidic, S., Sutton, M. A., Hunsche, M., et al. (2018). Camouflaged as 'degraded wax', hygroscopic aerosols contribute to leaf desiccation, tree mortality, and forest decline. Environ. Res. Lett. 13:085001. doi: 10.1088/1748-9326/aad346

Cardon, Z. G., Mott, K. A., and Berry, J. A. (1994). Dynamics of patchy stomatal movements, and their contribution to steady-state and oscillating stomatal conductance calculated with gas-exchange techniques. Plant Cell Environ. 17, 995-1007. doi: 10.1111/j.1365-3040.1994.tb02033.x

Cheeseman, J. M. (1991). PATCHY: simulating and visualizing the effects of stomatal patchiness on photosynthetic CO2 exchange studies. Plant Cell Environ. 14, 593-599. doi: 10.1111/j.1365-3040.1991.tb01530.x

Cowan, I. R., and Farquhar, G. D. (1977). Stomatal function in relation to leaf metabolism and environment. Symp. Soc. Exp. Biol. 31, 471-505.

Downton, W. J., Loveys, B. R., and Grant, W. J. R. (1990). Salinity effects on the stomatal behaviour of grapevine. New Phytol. 116, 499-503. doi: 10.1111/j. 1469-8137.1990.tb00535.x
Downton, W. J. S., Loveys, B. R., and Grant, W. J. R. (1988). Non-uniform stomatal closure induced by water stress causes putative non-stomatal inhibition of photosynthesis. New Phytol. 110, 503-509. doi: 10.1111/j.1469-8137.1988. tb00289. $\mathrm{x}$

Dutcher, C. S., Wexler, A. S., and Clegg, S. L. (2010). Surface tensions of inorganic multicomponent aqueous electrolyte solutions and melts. J. Phys. Chem. A 114, 12216-12230. doi: 10.1021/jp105191z

Eckstein, J., Beyschlag, W., Mott, K. A., and Ryel, R. J. (1996). Changes in photon flux can induce stomatal patchiness. Plant Cell Environ. 19, 1066-1075.

Eichert, T., Goldbach, H. E., and Burkhardt, J. (1998). Evidence for the uptake of large anions through stomatal pores. Bot. Acta 111, 461-466. doi: 10.1111/j. 1438-8677.1998.tb00733.x

Eichert, T., Kurtz, A., Steiner, U., and Goldbach, H. E. (2008). Size exclusion limits and lateral heterogeneity of the stomatal foliar uptake pathway for aqueous solutes and water suspended nanoparticles. Physiol. Plant. 134, 151-160. doi: 10.1111/j.1399-3054.2008.01135.x

Eiden, R., Burkhardt, J., and Burkhardt, O. (1994). Atmospheric aerosol particles and their role in the formation of dew on the surface of plant leaves. J. Aerosol Sci. 25, 367-376. doi: 10.1016/0021-8502(94)90087-6

Fanourakis, D., Heuvelink, E., and Carvalho, S. M. P. (2015). Spatial heterogeneity in stomatal features during leaf elongation: an analysis using Rosa hybrida. Funct. Plant Biol. 42, 737-745.

Fernandez, V., Bahamonde, H. A., Peguero-Pina, J. J., Gil-Pelegrin, E., SanchoKnapik, D., Gil, L., et al. (2017). Physico-chemical properties of plant cuticles and their functional and ecological significance. J. Exp. Bot. 19, 5293-5306. doi: $10.1093 / \mathrm{jxb} / \mathrm{erx} 302$

Gorton, H. L., Williams, W. E., and Binns, M. E. (1989). Repeated measurements of aperture for individual stomates. Plant Physiol. 89, 387-390. doi: 10.1104/pp. 89.2.387

Grantz, D. A. (1990). Plant-response to atmospheric humidity. Plant Cell Environ. 13, 667-679. doi: 10.1111/j.1365-3040.1990.tb01082.x

Grantz, D. A., Zinsmeister, D., and Burkhardt, J. (2018). Ambient aerosol increases minimum leaf conductance and alters the aperture-flux relationship as stomata respond to vapor pressure deficit (VPD). New Phytol. 219, 275-286. doi: 10. 1111/nph.15102

Gunasekera, D., and Berkowitz, G. A. (1992). Heterogeneous stomatal closure in response to leaf water deficits is not a universal phenomenon. Plant Physiol. 98, 660-665. doi: 10.1104/pp.98.2.660

Haefner, J. W., Buckley, T. N., and Mott, K. A. (1997). A spatially explicit model of patchy stomatal responses to humidity. Plant Cell Environ. 20, 1087-1097. doi: 10.1046/j.1365-3040.1997.d01-137.x

Hanson, D. T., Stutz, S. S., and Boyer, J. S. (2016). Why small fluxes matter: the case and approaches for improving measurements of photosynthesis and (photo)respiration. J. Exp. Bot. 67, 3027-3039. doi: 10.1093/jxb/erw139

Kaiser, H. (2009). The relation between stomatal aperture and gas exchange under consideration of pore geometry and diffusional resistance in the mesophyll. Plant Cell Environ. 32, 1091-1098. doi: 10.1111/j.1365-3040.2009.01990.x

Kaiser, H. (2014). Stomatal uptake of mineral particles from a sprayed suspension containing an organosilicone surfactant. J. Plant Nutr. Soil Sci. 177, 869-874. doi: 10.1002/jpln.201300607

Kaiser, H., and Kappen, L. (1997). In situ observations of stomatal movements in different light-dark regimes: the influence of endogenous rhythmicity and long-term adjustments. J. Exp. Bot. 48, 1583-1589. doi: 10.1093/jexbot/48.313. 1583

Kaiser, H., and Kappen, L. (2000). In situ observation of stomatal movements and gas exchange of Aegopodium podagraria L. In the understorey. J. Exp. Bot. 51, 1741-1749. doi: 10.1093/jexbot/51.351.1741

Kamakura, M., and Furukawa, A. (2008). Responses of individual stomata in Ipomoea pes-caprae to various CO2 concentrations. Physiol. Plant. 132, 255 261. doi: 10.1111/j.1399-3054.2007.01003.x

Kamakura, M., Kosugi, Y., Muramatsu, K., and Muraoka, H. (2012). Simulations and observations of patchy stomatal behavior in leaves of Quercus crispula, a cool-temperate deciduous broad-leaved tree species. J. Plant Res. 125, 339-349. doi: 10.1007/s10265-011-0460-8

Kappen, L., Andresen, G., and Losch, R. (1987). In situ observations of stomatal movements. J. Exp. Bot. 38, 126-141.

Kerstiens, G. (1996). Cuticular water permeability and its physiological significance. J. Exp. Bot. 47, 1813-1832. doi: 10.1093/jxb/47.12.1813 
Kuki, K. N., Oliva, M. A., Pereir, A. E. G., Costa, A. C., and Cambraia, J. (2008). Effects of simulated deposition of acid mist and iron ore particulate matter on photosynthesis and the generation of oxidative stress in Schinus terebinthifolius Radii and Sophora tomentosa L. Sci. Total Environ. 403, 207-214. doi: 10.1016/ j.scitotenv.2008.05.004

Laisk, A., Oja, V., and Kull, K. (1980). Statistical distribution of stomatal apertures of Vicia faba and Hordeum vulgare and the Spannungsphase of stomatal opening. J. Exp. Bot. 31, 49-58.

Lawson, T., Weyers, J., and A'Brook, R. (1998). The nature of heterogeneity in the stomatal behavior of Phaseolus vulgaris L. primary leaves. J. Exp. Bot. 49, 1387-1395. doi: 10.1093/jxb/49.325.1387

Loreto, F., and Sharkey, T. D. (1990). Low humidity can cause uneven photosynthesis in olive (Olea europaea L.) leaves. Tree Physiol. 6, 409-415. doi: 10.1093/treephys/6.4.409

Maier-Maercker, U. (1983). The role of peristomatal transpiration in the mechanism of stomatal movement. Plant Cell Environ. 6, 369-380. doi: 10. 1111/j.1365-3040.1983.tb01269.x

Monteith, J. L. (1957). Dew. Q. J. R. Meteorol. Soc. 83, 322-341.

Mott, K. A., and Buckley, T. N. (1998). Stomatal heterogeneity. J. Exp. Bot. 49, 407-417. doi: 10.1093/jexbot/49.suppl_1.407

Mott, K. A., and Buckley, T. N. (2000). Patchy stomatal conductance: emergent collective behavior of stomata. Trends Plant Sci. 5, 258-262. doi: 10.1016/ s1360-1385(00)01648-4

Mott, K. A., Denn, E. F., and Powell, J. (1997). Interactions among stomata in response to perturbations in humidity. Plant Cell Environ. 20, 1098-1107. doi: 10.1046/j.1365-3040.1997.d01-138.x

Mott, K. A., and Franks, P. J. (2001). The role of epidermal turgor in stomatal interactions following a local perturbation in humidity. Plant Cell Environ. 24, 657-662. doi: 10.1046/j.0016-8025.2001.00705.x

Mott, K. A., and Parkhurst, D. F. (1991). Stomatal responses to humidity in air and helox. Plant Cell Environ. 14, 509-515. doi: 10.1111/j.1365-3040.1991.tb0 1521.x

Mott, K. A., and Peak, D. (2007). Stomatal patchiness and task-performing networks. Ann. Bot. 99, 219-226. doi: 10.1093/aob/mcl234

Mott, K. A., Shope, J. C., and Buckley, T. N. (1999). Effects of humidity on lightinduced stomatal opening: evidence for hydraulic coupling among stomata. J. Exp. Bot. 50, 1207-1213. doi: 10.1093/jxb/50.336.1207

Nardini, A., Gortan, E., Ramani, M., and Salleo, S. (2008). Heterogeneity of gas exchange rates over the leaf surface in tobacco: an effect of hydraulic architecture? Plant Cell Environ. 31, 804-812. doi: 10.1111/j.1365-3040.2008. 01798.x

Osmond, C. B., Kramer, D., and Luttge, U. (1999). Reversible, water stress-induced non-uniform chlorophyll fluorescence quenching in wilting leaves of Potentilla reptans may not be due to patch stomatal responses. Plant Biol. 1, 618-624. doi: 10.1111/j.1438-8677.1999.tb00272.x

Pariyar, S., Eichert, T., Goldbach, H. E., Hunsche, M., and Burkhardt, J. (2013). The exclusion of ambient aerosols changes the water relations of sunflower (Helianthus annuus) and bean (Vicia faba) plants. Environ. Exp. Bot. 88, 43-52. doi: 10.1016/j.envexpbot.2011.12.031

Pospisilova, J., and Santrucek, J. (1994). Stomatal patchiness. Biol. Plant. 36, 481-510. doi: 10.1007/bf02921169

Pringle, K. J., Tost, H., Pozzer, A., Poschl, U., and Lelieveld, J. (2010). Global distribution of the effective aerosol hygroscopicity parameter for CCN activation. Atmos. Chem. Phys. 10, 5241-5255. doi: 10.5194/acp-10-5241-2010
Putaud, J.-P., Van Dingenen, R., Alastuey, A., Bauer, H., Birmili, W., Cyrys, J., et al. (2010). A European aerosol phenomenology 3. Physical and chemical characteristics of particulate matter from 60 rural, urban, and kerbside sites across Europe. Atmos. Environ. 44, 1308-1320. doi: 10.1016/j.atmosenv.2009. 12.011

Saxe, H. (1979). A structural and functional study of the coordinated reactions of individual Commelina communis L. stomata (Commelinaceae). Am. J. Bot. 66, 1044-1052. doi: 10.1002/j.1537-2197.1979.tb06320.x

Sharkey, D. T., and Seemann, J. R. (1989). Mild water stress effects on carbonreduction-cycle intermediates, ribulose bisphosphate carboxylase activity, and spatial homogeneity of photosynthesis in intact leaves. Plant Physiol. 89, 10601065. doi: $10.1104 /$ pp.89.4.1060

Siebke, K., and Weis, E. (1995). Assimilation images of leaves of Glechoma hederacea: analysis of nonsynchronous stomata related oscillations. Planta 196, 155-165.

Smith, S., Weyers, J. D. B., and Berry, W. G. (1989). Variation in stomatal characteristics over the lower surface of Commelina communis leaves. Plant Cell Environ. 12, 653-659.

Spence, R. D. (1987). The problem of variability in stomatal responses, particularly aperture variance, to environmental and experimental conditions. New Phytol. 107, 303-315. doi: 10.1111/j.1469-8137.1987.tb00182.x

Spence, R. D., Sharpe, P. J. H., Powell, R. D., and Rogers, C. A. (1983). Epidermal and guard cell interactions on stomatal aperture in epidermal strips and intact leaves. Ann. Bot. 52, 1-12. doi: 10.1093/oxfordjournals.aob.a086538

Sperry, J. S., Venturas, M. D., Anderegg, W. R. L., Mencuccini, M., Mackay, D. S., Wang, Y., et al. (2017). Predicting stomatal responses to the environment from the optimization of photosynthetic gain and hydraulic cost. Plant Cell Environ. 40, 816-830. doi: $10.1111 /$ pce. 12852

Terashima, I. (1992). Anatomy of non-uniform leaf photosynthesis. Photosynth. Res. 31, 195-212. doi: 10.1007/bf00035537

Terashima, I., Wong, S.-C., Osmond, C. B., and Farquhar, G. D. (1988). Characterization of non-uniform photosynthesis induced by abscisic acid in leaves having different mesophyll anatomies. Plant Cell Physiol. 29, 385-394.

Tsigaridis, K., Krol, M., Dentener, F. J., Balkanski, Y., Lathiere, J., Metzger, S., et al. (2006). Change in global aerosol composition since preindustrial times. Atmos. Chem. Phys. 6, 5143-5162. doi: 10.5194/acp-6-5143-2006

Weyers, J. D. B., and Lawson, T. (1997). Heterogeneity in stomatal characteristics. Adv. Bot. Res. 26, 317-351.

Yang, J., Chang, Y. M., and Yan, P. B. (2015). Ranking the suitability of common urban tree species for controlling PM2.5 pollution. Atmos. Pollut. Res. 6, 267-277. doi: 10.5094/apr.2015.031

Conflict of Interest: The authors declare that the research was conducted in the absence of any commercial or financial relationships that could be construed as a potential conflict of interest.

Copyright (C) 2020 Grantz, Karr and Burkhardt. This is an open-access article distributed under the terms of the Creative Commons Attribution License (CC BY). The use, distribution or reproduction in other forums is permitted, provided the original author(s) and the copyright owner(s) are credited and that the original publication in this journal is cited, in accordance with accepted academic practice. No use, distribution or reproduction is permitted which does not comply with these terms. 